\title{
Neurotrophin-3 Gradients Established by Lentiviral Gene Delivery Promote Short-Distance Axonal Bridging beyond Cellular Grafts in the Injured Spinal Cord
}

\author{
Laura Taylor, ${ }^{1}$ Leonard Jones, ${ }^{1}$ Mark H. Tuszynski, ${ }^{1,2}$ and Armin Blesch ${ }^{1}$ \\ ${ }^{1}$ Department of Neurosciences, University of California, San Diego, La Jolla, California 92093, and ${ }^{2}$ Veterans Administration Medical Center, San Diego, \\ California 92165
}

\begin{abstract}
Neurotrophic factor delivery to sites of spinal cord injury (SCI) promotes axon growth into but not beyond lesion sites. We tested the hypothesis that sustained growth factor gradients beyond regions of SCI will promote significant axonal bridging into and beyond lesions. Adult rats underwent $\mathrm{C} 3$ lesions to transect ascending dorsal column sensory axons, and autologous bone marrow stromal cells were grafted into the lesion to provide a cellular bridge for growth into the injured region. Concurrently, lentiviral vectors expressing neurotrophin-3 (NT-3) or green fluorescent protein (GFP) (controls) were injected into the host cord rostral to the lesion to promote axon extension beyond the graft/lesion. Four weeks later, NT-3 gradients beyond the lesion were detectable by ELISA in animals that received NT-3-expressing lentiviral vectors, with highest average NT-3 levels located near the rostral vector injection site. Significantly more ascending sensory axons extended into tissue rostral to the lesion site in animals injected with NT-3 vectors compared with GFP vectors, but only if the zone of NT-3 vector transduction extended continuously from the injection site to the graft; any "gap" in NT-3 expression from the graft to rostral tissue resulted in axon bridging failure. Despite axon bridging beyond the lesion, regenerating axons did not continue to grow over very long distances, even in the presence of a continuing growth factor gradient beyond the lesion. These findings indicate that a localized and continuous gradient of NT-3 can achieve axonal bridging beyond the glial scar, but growth for longer distances is not sustainable simply with a trophic stimulus.
\end{abstract}

Key words: NT-3; spinal cord injury; ascending sensory; gene therapy; lentivirus; regeneration

\section{Introduction}

After spinal cord injury (SCI) in adult mammals, axons do not regenerate and essential neuronal connections are permanently lost. The failure of injured axons to regenerate results from a combination of factors, including a lack of permissive growth substrates within lesion sites, the presence of inhibitory molecules that impair axonal outgrowth (Filbin, 2003; Silver and Miller, 2004), lack of neurotrophic support (Tuszynski et al., 1996; Bradbury et al., 1999; Liu et al., 1999a), and the failure of CNS neurons to maximally activate cellular growth programs after injury (Snider et al., 2002). However, the application of neurotrophic factors, such as the neurotrophins, to injured axons or neuronal cell bodies can promote the survival and growth of adult neurons after injury (Schnell et al., 1994; Tetzlaff et al., 1994; Xu et al., 1995; Grill et al., 1997a; Kobayashi et al., 1997; Ye and Houle, 1997; Jakeman et al., 1998; Liu et al., 1999b; Blits et al., 2000; Ramer et al., 2000; Bamber et al., 2001; Coumans et al., 2001; Himes et al., 2001; Lu et al., 2001; Plunet et al., 2002),

Received Feb. 17, 2006; revised June 30, 2006; accepted Aug. 3, 2006

This work was supported by the California Roman Reed Spinal Cord Injury Research Fund, Paralyzed Veterans of America, International Spinal Research Trust, and National Institutes of Health Grants NS46466 and NS047101.

Correspondence should be addressed to Dr. Armin Blesch, Department of Neurosciences-0626, University of California, San Diego, 9500 Gilman Drive, La Jolla, CA 92093-0626. E-mail: ablesch@ucsd.edu.

DOI:10.1523/JNEUROSCI.0734-06.2006

Copyright $\odot 2006$ Society for Neuroscience $\quad$ 0270-6474/06/269713-09\$15.00/0 suggesting that the regenerative capacity of adult CNS neurons may be enhanced.

The transplantation of genetically modified cells expressing neurotrophic factors to lesion sites has been investigated as one means to augment axonal regeneration after SCI (Menei et al., 1998; Tuszynski et al., 2002; Ruitenberg et al., 2003; Blesch et al., 2004; Lu et al., 2005). Cells transplanted into lesion sites can provide a permissive substrate for axonal extension through lesioned areas and, when transduced to overexpress growth factors, can also provide neurotrophic support for growing axons. Although this approach generates relatively robust axonal growth into lesion sites, axons rarely exit the graft to reinnervate the distal host spinal cord. The lack of true axonal bridging after growth factor delivery solely within spinal cord lesion sites is in fact predicted by the observation that axons extend down gradients of diffusible molecules. For example, during nervous system development and in models of regeneration, growth cones extend along gradients of diffusible chemoattractive or repulsive factors (Tessier-Lavigne, 1994). Several studies indicate that neurotrophins and other diffusible proteins may provide such guidance cues for embryonic and regenerating axons (Letourneau, 1978; Gundersen and Barrett, 1979; Gallo et al., 1997; Paves and Saarma, 1997; Ringstedt et al., 1997; Houweling et al., 1998; Zhang et al., 1998; Kirik et al., 2000; Romero et al., 2001; Tucker et al., 2001; Dontchev and Letourneau, 2002; Zhou et al., 2003; 


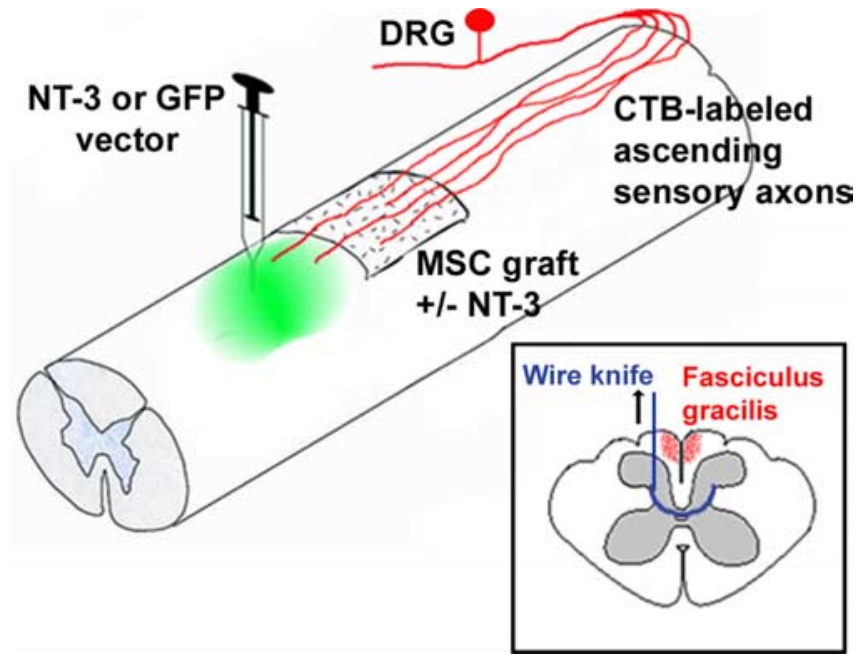

Figure 1. Schematic illustrating experimental design. Adult rats underwent dorsal column wire knife lesions at $\mathrm{C} 3$ to transect ascending sensory axons (inset). Autologous bone marrow stromal cells (either naive or modified in vitro to express NT-3) were grafted into the lesion site, and lentiviral vectors expressing NT-3 or GFP (control) were injected into the spinal cord $2.5 \mathrm{~mm}$ rostral to the lesion site. After 4 weeks, animals were killed for ELISA or ascending sensory axons were traced by injection of CTB into the sciatic nerve, and animals were killed $3 \mathrm{~d}$ later for histology.

Genc et al., 2004; Tessarollo et al., 2004). Thus, provision of neurotrophic factors both within and beyond a lesion site could establish an extended gradient enabling axons to grow not only into, but also beyond, cellular grafts in lesion sites.

We have shown previously that transected ascending sensory axons extensively penetrate cellular grafts expressing neurotrophin-3 (NT-3) but that axons do not grow beyond lesion sites (Lu et al., 2003). In addition, if single injections of NT-3 protein within and beyond lesion sites are combined with cAMP administration, axons will bridge beyond the lesion ( $\mathrm{Lu}$ et al., 2004). In the present study, we examined whether provision of continuous, high levels of NT-3 by lentiviral-mediated delivery beyond a lesion site would promote axonal bridging. We find that axons indeed bridge beyond the lesion if provided a continuous gradient of NT-3 but that long-distance growth is not supported.

\section{Materials and Methods}

Production of lentiviral vectors. The vector pLV (Pfeifer et al., 2002) was used to construct NT-3-secreting and control [green fluorescent protein (GFP)-expressing] vectors (Fig. 1). The NT-3 lentiviral vector was constructed by cloning the complete human NT-3 cDNA plus Kozak consensus sequence into the BamHI and EcoRI sites of the vector pIRES2EGFP (Clontech, Palo Alto, CA). The resulting plasmid was digested with NheI and BsrGI to excise the fragment containing huNT-3-IRES-EGFP. This fragment was cloned into the NheI and BsrGI sites of the vector pLV-GFP, thereby replacing the GFP cassette. NT-3 or GFP expression was driven by the cytomegalovirus/ $\beta$-actin hybrid promoter (CAG) (Niwa et al., 1991).

Third-generation lentiviral vector plasmids with a split genome packaging system were used for the production of human immunodeficiency virus (HIV) vectors. In vitro and in vivo, transgene expression was initiated from the CAG promoter within $48 \mathrm{~h}$. Vesicular stomatitis virus glycoprotein G (VSV-G) pseudotyped lentivirus was generated by transient cotransfection of a vector construct $(15 \mu \mathrm{g})$ with the VSV-Gexpressing construct pMDG $(5 \mu \mathrm{g})$ and the packaging construct $(10 \mu \mathrm{g})$ into HEK293T cells, as described previously (Naldini et al., 1996; Blesch, 2004). High-titer stocks of HIV vectors were prepared by ultracentrifugation. Titers of GFP-expressing virus were determined by infection of HEK293T cells using serial dilutions. After 48 h, GFP-expressing colonies
Table 1. Experimental groups

\begin{tabular}{lllll}
\hline Groups & Cells in lesion site & $\begin{array}{l}\text { Lentiviral vector injected } \\
\text { rostral to lesion }\end{array}$ & $\begin{array}{l}\text { Anatomical } \\
\text { analysis }\end{array}$ & ELISA \\
\hline 1 & MSC-NT-3 & Lenti-NT-3 & $n=11$ & $n=6$ \\
2 & MSC & Lenti-NT-3 & $n=10$ & $n=6$ \\
3 & MSC-NT-3 & Lenti-GFP & $n=8$ & $n=6$ \\
4 & MSC & Lenti-GFP & $n=8$ & $n=6$ \\
5 & MSC-NT-3 & No lentivirus & & $n=6$ \\
6 & MSC & No lentivirus & & $n=5$ \\
7 & No lesion & No lentivirus & $n=4$ & $n=3$ \\
\hline
\end{tabular}

Animals were divided into four groups (groups 1-4) based on the type of cells grafted to the lesion site and the type of lentiviral vector injected. Cellular grafts consisted of MSC or MSC-NT-3. Lentiviral vectors expressed either GFP or NT-3 and GFP. Animals were used for ELISA or immunocytochemical analysis. Two additional groups of animals (groups 5,6) received MSC or MSC-NT-3 grafts, but no lentivirus injection, and were used to determine levels of NT-3 in dissected graft segments by ELISA. A final group of animals (group 7) remained unlesioned, received no graft cells or lentivirus injection, and was used as an immunohistochemical control to identify normal CTB labeling or to determine NT-3 levels in naive spinal cord.

were quantified for each dilution to determine infectious units (IU) per milliliter. Vector stocks were also assayed for p24 antigen levels using an HIV-1 p24-specific ELISA kit (DuPont, Billerica, MA) as described previously (Naldini et al., 1996). NT-3 vector preparations contained 112 $134 \mu \mathrm{g} / \mathrm{ml} \mathrm{p} 24$ and $4 \times 10^{7}$ to $1.5 \times 10^{8} \mathrm{IU} / \mathrm{ml}$. Control vector preparations contained $95-112 \mu \mathrm{g} / \mathrm{ml} \mathrm{p} 24$ and $1-5 \times 10^{8} \mathrm{IU} / \mathrm{ml}$.

Isolation of marrow stromal cells to be used as graft cells. Rat primary marrow stromal cells (MSCs) were isolated according to the method of Azizi et al. (1998). Briefly, Fischer 344 adult female rats were anesthetized with a combination $(2 \mathrm{ml} / \mathrm{kg})$ of ketamine $(25 \mathrm{mg} / \mathrm{ml})$, xylazine $(1.3$ $\mathrm{mg} / \mathrm{ml})$, and acepromazine $(0.25 \mathrm{mg} / \mathrm{ml})$ and decapitated, and tibias and femurs were dissected. After removing the end of each bone, $5 \mathrm{ml}$ of $\alpha$-MEM (Invitrogen, Carlsbad, CA) was injected into the central canal of the bone to extrude marrow. Cells were cultured in $\alpha$-MEM (Invitrogen) supplemented with $20 \%$ fetal bovine serum and antibiotics. Nonadherent cells were removed after $24 \mathrm{~h}$. Cells were passaged twice and either frozen or transduced with Moloney murine leukemia virus-based retroviral vectors for the expression of NT-3. Before grafting, cells were thawed and cultured in the same media as above.

Transduction of marrow stromal cells with retroviral vectors before grafting. Syngenic MSCs were genetically modified to produce and secrete human NT-3 using a stable PA317 retrovirus producer cell line as described previously (Grill et al., 1997a). Conditioned media from producer cultures were used to infect MSCs, and transduced cells were selected for G418 resistance ( $100 \mu \mathrm{g} / \mathrm{ml})$ for $11 \mathrm{~d}$. After selection, cells were grown to confluency, and $24 \mathrm{~h}$ supernatants were collected for ELISA analysis of NT-3 protein expression (NT-3 Emax ImmunoAssay System; Promega, Madison, WI). Transduced MSCs produced $\sim 165$ ng of NT$3 / 10^{6}$ cells per $24 \mathrm{~h}$.

Bromodeoxyuridine-labeling of marrow stromal cells in vitro. MSCs were cultured in media containing $2 \mu \mathrm{M}$ bromodeoxyuridine (BrdU) for $72 \mathrm{~h}$ before surgery, with media exchanged every $24 \mathrm{~h}$. Before collection for surgery, cells were washed three times with PBS, isolated by trypsinization followed by centrifugation, and then washed an additional time in $10 \mathrm{ml}$ of PBS.

Animal subjects. Adult female Fischer 344 rats $(n=79)$ weighing $150-$ $200 \mathrm{~g}$ were used. Institutional, National Institutes of Health (NIH), and Society for Neuroscience guidelines on animal care were followed. Animals were divided into groups based on the type of cells grafted to the lesion site and the type of lentiviral vector received (Table 1, Fig. 1). Graft cells were either naive marrow stromal cells (MSC) or marrow stromal cells transduced in vitro to express NT-3 (MSC-NT-3). Lentiviral vectors expressed either GFP only (Lenti-GFP), or NT-3 plus GFP [with GFP expressed from an internal ribosome entry site (Lenti-NT-3)] (supplemental Fig. 1, available at www.jneurosci.org as supplemental material). Additional unlesioned animals without graft or lentivirus injections served as controls for immunolabeling or ELISA.

Lesion surgery and vector injections. Animals underwent a laminectomy at spinal level C2/C3. Dorsal column lesions were made at the caudal aspect of C3 using a David Kopf Instruments (Tujunga, CA) microwire device (Fig. 1). After fixation in a spinal stereotaxic unit, a small dural 
incision was made. The wire knife was lowered into the spinal cord to a depth of $1.1 \mathrm{~mm}$ ventral to the dorsal cord surface and $1.1 \mathrm{~mm}$ to the left of the midline. The tip of the wire knife was extruded, forming a 2.25$\mathrm{mm}$-wide arc that was raised to the dorsal surface of the cord, transecting the dorsal funiculus including the ascending (sensory) and descending (corticospinal) axon tracts. To ensure complete axotomy of the entire dorsal column, spinal tissue was compressed against the microwire knife surface using a microaspiration pipette until all visible white matter was transected.

Immediately after the lesion, $2 \mu \mathrm{l}(\sim 75,000$ cells/ $\mu \mathrm{l})$ of MSC or MSCNT-3 were injected through a small hole in the dura mater into the lesion space. Cells were injected using a pulled glass micropipette attached to a Picospritzer II (General Valve, Fairfield, NJ). Lentiviral vectors $(2.5 \mu \mathrm{l})$ were injected superficially through pulled glass capillaries $2.5 \mathrm{~mm}$ rostral to the lesion site into the spinal cord midline at a depth of 0.5 and $1 \mathrm{~mm}$ $(1.25 \mu \mathrm{l}$ at each depth), at a rate of $1 \mu \mathrm{l} / \mathrm{min}$. Pipettes were left in place for $1 \mathrm{~min}$ after the injection and were then slowly withdrawn. Overlying muscle layers were sutured and the skin was stapled. Animals were killed after 4 weeks.

Transganglionic labeling of ascending sensory projections. Animals used for histological analysis $(n=41)$ received injections of cholera toxin B (CTB) $(1 \%, 2 \mu \mathrm{l}$; List Biologic, Campbell, CA) into the right and left sciatic nerves $3 \mathrm{~d}$ before death to label ascending sensory projections.

Measurement of in vivo gradients of NT-3 generated by lentiviral gene delivery. The ability of lentiviral vectors expressing NT-3 to establish trophic factor gradients within and beyond sites of SCI were examined in the groups indicated in Table 1. Production of NT-3 protein was measured in transverse segments of spinal cords or dissected graft tissue using an NT-3-specific ELISA. Four weeks after lesion/injection, animals received an overdose of anesthesia and were transcardially perfused with 50 $\mathrm{ml}$ of ice-cold $0.1 \mathrm{M}$ PBS. To obtain isolated graft tissue, the graft region was dissected from the surrounding spinal cord and immediately frozen. An equivalent region of tissue from the dorsal half of the spinal cord was dissected from intact animals. To obtain transverse spinal cord segments, the spinal cord was rapidly dissected and the lesion center was located under a dissection microscope. A 7-mm-long section of spinal cord, extending $5 \mathrm{~mm}$ rostral and $2 \mathrm{~mm}$ caudal to the lesion center, was carefully and rapidly dissected and immediately frozen. Spinal cords were embedded into TBS Tissue Freezing Media (Triangle Biomedical Sciences. Durham, NC) on dry ice. A cryostat was used to cut spinal cords into $100-\mu \mathrm{m}$-thick transverse sections, which were pooled into $1 \mathrm{~mm}$ segments (10 adjacent $100 \mu \mathrm{m}$ segments) for ELISA.

The $1 \mathrm{~mm}$ segments, dissected graft tissue, or intact spinal cord segments were weighed, lysed by sonication in lysis buffer ( $40 \mu \mathrm{l} / \mathrm{mg}$ tissue $)$ containing protease inhibitors (1 $\mathrm{mm}$ phenylmethylsulfonyl fluoride) and a protease inhibitor cocktail (Roche Diagnostics, Mannheim, Germany), centrifuged $10 \mathrm{~min}$ at $14,000 \mathrm{rpm}$ at $4^{\circ} \mathrm{C}$, and used for NT-3 ELISA according to the instructions of the manufacturer (NT-3 Emax ImmunoAssay System; Promega). For transverse segments, overall levels of NT-3 were compared between the four groups by repeated-measures ANOVA, followed by Fisher's post hoc test. Levels of NT-3 in different 1 $\mathrm{mm}$ segments within a group were also compared by Fisher's post hoc tests. For dissected graft tissue and intact spinal cord analyses, groups were compared by ANOVA, followed by Fisher's post hoc test. A significance criterion of $p<0.05$ was used for all statistical tests.

Immunohistochemical analysis of spinal cord and brainstem sections. Animals used for immunolabeling were transcardially perfused with 100 $\mathrm{ml}$ of cold PBS, followed by $300 \mathrm{ml}$ of $4 \%$ paraformaldehyde in phosphate buffer. Spinal cords and brainstems were removed, postfixed overnight in $4 \%$ paraformaldehyde, and cryoprotected in $0.1 \mathrm{M}$ phosphate buffer containing $30 \%$ sucrose at $4^{\circ} \mathrm{C}$. For spinal cords, tissue was blocked in TBS Tissue Freezing Media (Triangle Biomedical Sciences) on dry ice, and sagittal sections were cut at $35 \mu \mathrm{m}$ intervals with a cryostat. Every seventh section was immediately mounted on glass slides for Nissl staining. For brainstems, blocked tissue was cut in the coronal plane at 40 $\mu \mathrm{m}$ thickness, and every ninth section was immediately mounted for Nissl staining.

Spinal cord sections were triple labeled for CTB using streptavidinHRP light-level immunohistochemistry, followed by GFP and glial fibril- lary acidic protein (GFAP) fluorescent immunolabeling. The following immunocytochemical markers were used: goat anti-CTB (1:80,000; List Biologic) to detect ascending sensory axons; GFAP (monoclonal, 1:1000; Chemicon, Temecula, CA) to label astrocytes; and rabbit anti-GFP (1: 750; Invitrogen) to label vector-transduced cells. Immunocytochemical labeling for CTB was performed first with streptavidin-HRP-based lightlevel immunohistochemistry using free-floating sections in the following protocol: (1) overnight incubation in primary antibodies at $4^{\circ} \mathrm{C} ;(2)$ incubation for $1 \mathrm{~h}$ with biotinylated secondary antibodies (1:200; Vector Laboratories, Burlingame, CA) at room temperature; (3) 1 h incubation with avidin-biotinylated peroxidase complex (1:150; Vector Elite kit; Vector Laboratories) at room temperature; and (4) treatment for $4 \mathrm{~min}$ with $0.05 \%$ solution of $3,3^{\prime}$-diaminobenzidine, $0.01 \% \mathrm{H}_{2} \mathrm{O}_{2}$, and $0.04 \%$ nickel chloride at room temperature. Fluorescence immunohistochemistry for GFP and GFAP was then performed on the same sections according to the following protocol: (1) overnight incubation in primary antibody; and then (2) $2.5 \mathrm{~h}$ incubation with fluorescent-conjugated secondary antibodies (donkey anti-rabbit Alexa-488 at 1:150; donkey anti-mouse Alexa 594 at 1:200; Invitrogen). Brainstem sections were immunolabeled for CTB using the same streptavidin-HRP-based lightlevel procedure as described above for spinal cord. Labeled sections were mounted and coverslipped with Cytoseal 60 mounting media (Richard Allen Scientific, Kalamazoo, MI).

Quantification of axonal profiles distal to the lesion. To determine the number of CTB-labeled axons that extended beyond the dorsal column lesion site, one-of-seven $35 \mu \mathrm{m}$ sagittal spinal cord sections triple labeled for CTB, GFAP, and GFP were examined under fluorescence and transmission light microscopy by an observer blinded to group identity. GFAP labeling of astrocytes was used to identify the lesion boundary. The rostral lesion border was defined as the region in which GFAP-labeled astrocytic cell bodies were found rostral to the lesion. Because this border was often irregular, a dorsoventral line representing the lesion edge was defined as the most rostral extent of the lesion site.

A calibrated reticle eyepiece was used to delineate regions 0-250, 250500 , and $500-1000 \mu \mathrm{m}$ rostral to the defined dorsoventral line, and CTB-labeled axonal profiles were quantified in each region at $200 \times$ and $400 \times$ magnification. Axons found in GFAP-labeled areas that were caudal to the defined dorsoventral line were counted and included in the number of profiles from $0-250 \mu \mathrm{m}$ from the lesion. The distance from the rostral lesion border to the first GFP-expressing cell (indicating the limit of the zone of lentiviral vector transduction) in the rostral spinal cord was also measured. For animals in which the zone of vector transduction was within $100 \mu \mathrm{m}$ of the lesion border, the average number of axonal profiles in each region, $0-250,250-500$, and 500-1000 $\mu \mathrm{m}$ from the lesion edge, was compared between the four treatment groups by ANOVA, followed by Fisher's post hoc analysis, using a significance criterion of $p<0.05$. To identify in greater detail the position of axons within the first $500 \mu \mathrm{m}$ distance from the rostral graft/host interface, an additional sagittal spinal cord series was analyzed as described above, except that axon numbers within $50 \mu \mathrm{m}$ segments, rather than $250 \mu \mathrm{m}$ segments, were quantified rostral to the GFAP border.

Quantification of axonal density and GFP labeling in cell grafts. In a series of sagittal sections consisting of every seventh $35-\mu \mathrm{m}$-thick section, two sections containing the most axon-dense grafts were selected for analysis by an observer blinded to group identity. For each section, $200 \times$ magnification photomicrographs indicating (1) GFAP labeling surrounding the lesion site, (2) CTB-labeled axonal profiles, and (3) GFP-labeled cells within the lesion site were obtained using Magnafire software (version 2.0; Karl Storz Imaging, Goleta, CA). Identical light, microscope, and camera settings were used for all image acquisition procedures. Using NIH ImageJ software (version ImageJ 1.33u; Wayne Rasband, NIH, Bethesda, MD), light-level images indicating CTBlabeled axonal profiles were converted to black and white binary images using appropriate threshold settings such that axonal profiles appeared black and background appeared white. Nonspecific labeling of objects other than axons, such as artifactual spots resulting from tissue processing, was edited from images as described previously (Lu et al., 2005). Area-matched fluorescent photographs of GFAP labeling were used to outline the graft/lesion area, and outlines were superimposed onto 
binary-converted light-level images. NIH ImageJ software was then used to measure black pixels per total pixels in the outlined graft area. In the same sections, an equivalent procedure was used to measure the density of GFP-labeled cells within the GFAP-defined lesion border.

Evaluation of lesion completeness. Incomplete lesions would result in CTB labeling of the nucleus gracilis in the causal medulla. In all subjects, the medulla was sectioned coronally at $40 \mu \mathrm{m}$ intervals, and every ninth section was labeled for CTB. Using transmission light microscopy and $200 \times$ and $400 \times$ magnification, an examiner blinded to group identity determined whether axons or terminals were evident. Four intact animals underwent CTB injections of both sciatic nerves as positive controls for medullary labeling.

Assessment of survival and differentiation of grafted marrow stromal cells. To examine whether grafted, BrdU-labeled MSCs survived in the lesion site, one-of-seven spinal cord sections were labeled for BrdU (sheep anti-BrdU, 1:250; Abcam, Cambridge, MA) in animals that received BrdU-labeled graft cells according to the HRP-based light-level procedure described above. To test whether BrdU-labeled MSCs differentiated into cells of a neural lineage, double immunolabeling was performed using the neural markers neuronal-specific nuclear protein (NeuN), GFAP, and ionized calcium binding adapter molecule (Iba) (for neurons, astrocytes, and macrophages/microglia, respectively) per established protocols (Yang et al., 2006). The following primary antibodies were used: BrdU (sheep, 1:200), NeuN (monoclonal, 1:250; Chemicon), GFAP (1:1000; Chemicon), or IbaI (rabbit, 1:1500; Wako, Richmond, VA). Representative sections from each experimental group were examined using thin-plane scanning confocal microscopy, and putatively double-labeled cells were reconstructed in $x-y, y-x$, and $x-z$ planes.

\section{Results}

Injections of lentiviral vectors establish a rostrocaudal gradient of NT-3 in the injured spinal cord

We tested the ability of lentiviral vectors expressing NT-3 to establish trophic factor gradients within and beyond sites of SCI using the experimental model illustrated in Figure 1. Lentiviral vectors expressed NT-3 and GFP (Lenti-NT-3) or GFP alone (Lenti-GFP) in controls (supplemental Fig. 1, available at www. jneurosci.org as supplemental material). To determine whether exogenous NT-3 formed a gradient beyond spinal cord lesion sites, NT-3 levels were quantified by ELISA in transverse spinal cord segments in four experimental groups (Table 1, groups 1-4). ELISA indicated that overall NT-3 protein levels were higher in subjects that received Lenti-NT-3 injections (Fig. 2A) compared with subjects that received Lenti-GFP injections (repeated-measures ANOVA, $p<0.001$; Fisher's post hoc analysis, $p<0.01)$. In animals that received Lenti-NT-3 injections, gradients of NT-3 were present distal to the lesion site. Peak NT-3 levels were detected in transverse spinal cord segments containing the lentiviral vector injection site $(125 \pm 50$ and $96 \pm 21 \mathrm{ng} / \mathrm{g}$, groups 1 and 2, respectively) and progressively diminished as a function of distance from the injection site toward the lesion. Animals that received Lenti-GFP injections did not show rostrocaudal gradients but exhibited consistently low levels of NT-3 in spinal cord segments distal to the lesion site $(\sim 0.4 \mathrm{ng} / \mathrm{g})$. These levels are similar to those reported previously in intact rat spinal cord ( $\sim 0.6 \mathrm{ng} / \mathrm{g})$ (Tokumine et al., 2003) and to those we measured in intact spinal cord (see below). In the two groups that received Lenti-GFP injections, animals that received MSC-NT-3 grafts exhibited twofold higher levels of NT-3 in the two spinal cord segments that included the lesion area than animals that received MSC grafts (Fig. $2 B$ ). These levels were substantially exceeded in Lenti-NT-3-injected animals.

The above analysis did not directly measure NT-3 levels within grafts because $1 \mathrm{~mm}$ spinal cord segments contained both graft and surrounding host spinal cord. To accurately measure
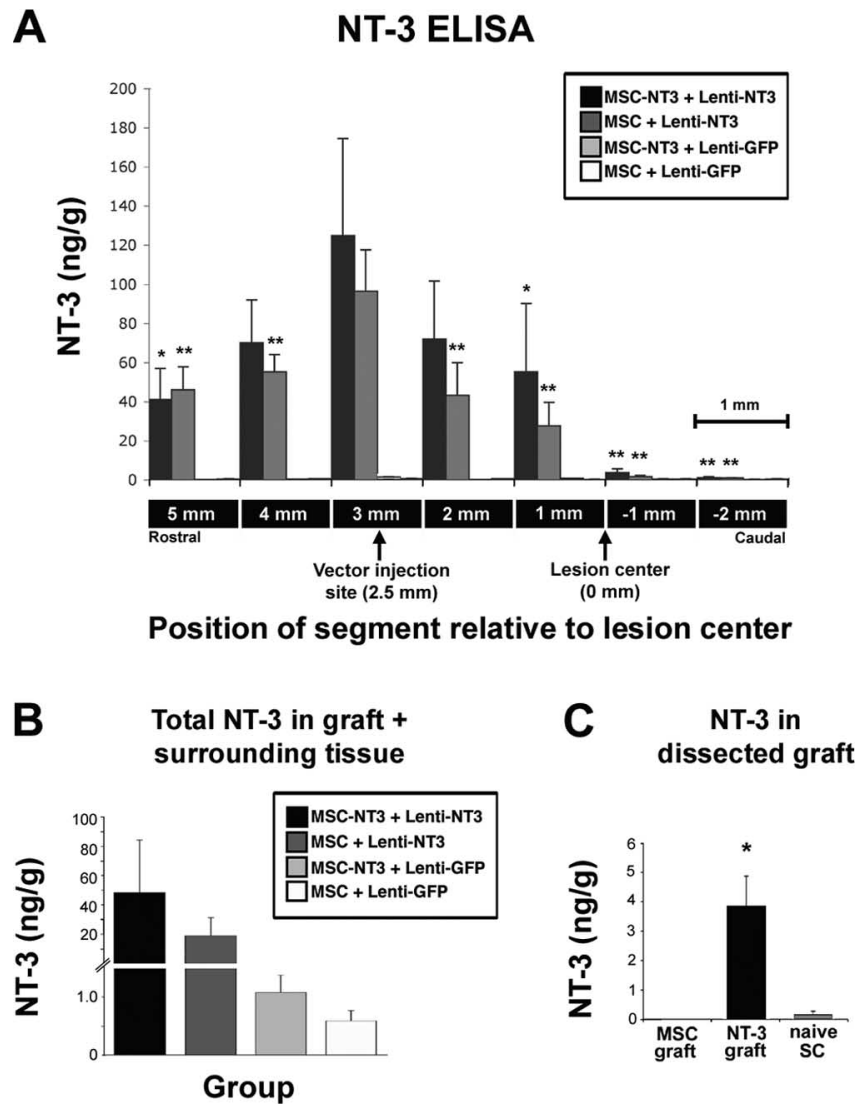

Figure 2. Injection of NT-3-expressing lentiviral vectors establishes a gradient of NT-3 in the injured spinal cord. $\boldsymbol{A}$, Four weeks after lesion and vector injection, spinal cords were sectioned into $1 \mathrm{~mm}$ segments as shown schematically on the $x$-axis. ELISA of individual $1 \mathrm{~mm}$ segments indicated that, in animals that received Lenti-NT-3 vector injections but not Lenti-GFP injections, a gradient of NT-3 was established rostral to the lesion site. For groups that received Lenti-NT-3 vector injections, asterisks indicate differences in NT-3 levels between the vector injection site ( $3 \mathrm{~mm}$ segment) and other segments in the same treatment group ( $p<0.001$, repeated-measures ANOVA; ${ }^{*} p<0.05,{ }^{* *} p<0.01$, Fisher's post hoc test). Values are mean \pm SEM. $\boldsymbol{B}$, Total NT-3 levels in the two spinal cord segments containing the graft/lesion site, and surrounding host tissue ( 1 and $-1 \mathrm{~mm}$ ), were greatly increased in animals that received LentiNT-3 vectors compared with Lenti-GFP vectors. In animals that received Lenti-GFP vectors, expression of NT-3 by genetically modified MSC grafts was evident as a twofold increase in total NT-3 detected in the 1 and $-1 \mathrm{~mm}$ spinal cord segments. Note that these measures include all host tissue within the spinal cord surrounding the lesion site, diluting amounts of NT-3 produced by NT-3-secreting MSCs in the lesion site. C, Levels of NT-3 were also measured in grafts specifically dissected from the lesion site, undiluted by surrounding host tissue. ELISA on this specific MSC graft tissue showed significantly higher levels of NT-3 in MSC-NT-3 grafted animals compared with MSC grafted animals or intact spinal cord $\left(p<0.01, \mathrm{ANOVA}^{*}{ }^{*} p<0.05\right.$, Fisher's post hoc test).

levels of NT-3 encountered by axons within the graft environment, ELISA was performed on dissected grafts in separate groups of animals (Table 1). After 4 weeks, MSC-NT-3 grafts produced significantly higher levels of NT-3 compared with the intact spinal cord and MSC grafts lacking NT-3 expression (Fig. $2 C$ ), indicating that MSC-NT-3 graft cells expressed supraphysiological levels of NT-3 for the duration of the experiment. Levels of NT-3 in MSC-NT-3 grafts (4 ng/g) were fivefold lower than levels of NT-3 in rostral spinal cord segments taken from animals that received Lenti-NT-3 injections (>20 ng/g). Thus, NT-3 levels generated by Lenti-NT-3 vectors were high enough that the presence of NT-3-expressing graft cells did not affect the formation of a rostral gradient. In contrast, levels of NT-3 in rostral spinal cord segments from Lenti-GFP-injected animals (0.4 

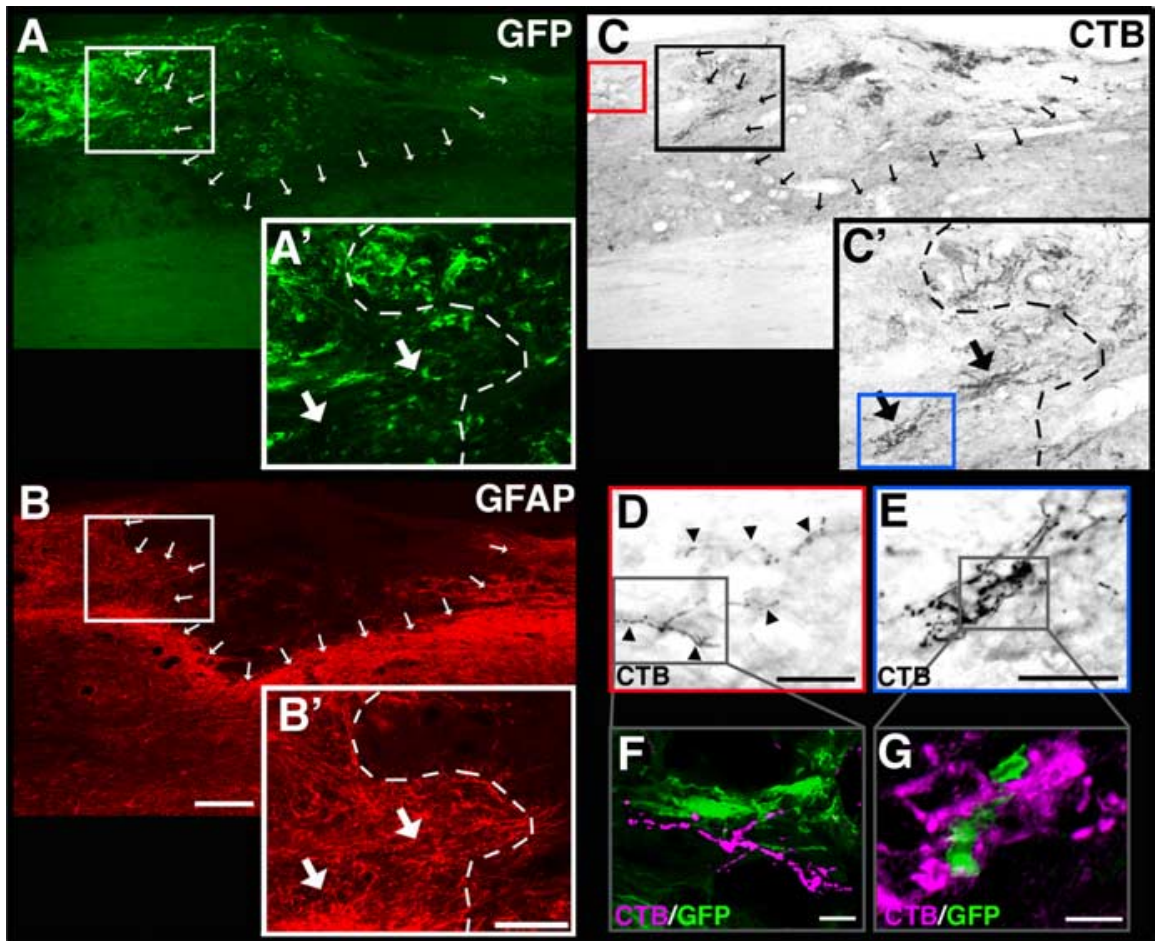

Figure 3. Ascending sensory axons extend beyond the graft/lesion site toward NT-3 vector-transduced cells. Triple immunolabeling for GFP to label NT-3 vector-transduced cells $(\boldsymbol{A})$, GFAP to indicate the extent of the lesion/graft site $(\boldsymbol{B})$, and CTB to label ascending sensory axons $(\boldsymbol{C})$ in a sagittally cut spinal cord 4 weeks after MSC-NT-3 cell grafting and Lenti-NT-3 injection. $\boldsymbol{A}^{\prime}-\boldsymbol{C}^{\prime}$, Higher magnification of the rostral host/graft interface shows axons $\left(\boldsymbol{C}^{\prime}\right.$; arrows) growing into GFAP-rich regions beyond the lesion site $\left(\boldsymbol{B}^{\prime}\right)$ in which vector-transduced cells express NT-3 $\left(\boldsymbol{A}^{\prime}\right) . \boldsymbol{D}, \boldsymbol{E}$, High magnification of red and blue boxed areas in $\boldsymbol{C}$ and $\boldsymbol{C}^{\prime}$, respectively. $\boldsymbol{F}, \boldsymbol{G}$, Higher magnification of boxed regions in $\boldsymbol{D}$ and $\boldsymbol{E}$ demonstrate the association of CTB-labeled axons (pseudocolored purple) with Lenti-NT-3 vector-transduced cells expressing the GFP reporter (green). Arrows in $\boldsymbol{A}-\boldsymbol{C}$ and dashed lines in $\boldsymbol{A}^{\prime}-\boldsymbol{C}^{\prime}$ indicate the graft/astrocyte border. Rostral is to the left, and dorsal to the top. Scale bars: $\boldsymbol{A}-\boldsymbol{C}, 200 \mu \mathrm{m} ; \boldsymbol{A}^{\prime}-\boldsymbol{C}^{\prime}, 100$ $\mu \mathrm{m} ; \boldsymbol{D}, \boldsymbol{E}, 50 \mu \mathrm{m} ; \boldsymbol{F}, \boldsymbol{G}, 10 \mu \mathrm{m}$.

$\mathrm{ng} / \mathrm{g}$ ) were lower than those measured in MSC-NT-3 grafts. Altogether, these data indicate that injection of lentiviral vectors expressing NT-3 can establish a successively increasing neurotrophic factor gradient away from the lesion site that is not achieved if NT-3 is expressed only by graft cells.

\section{A Growth Beyond Graft}
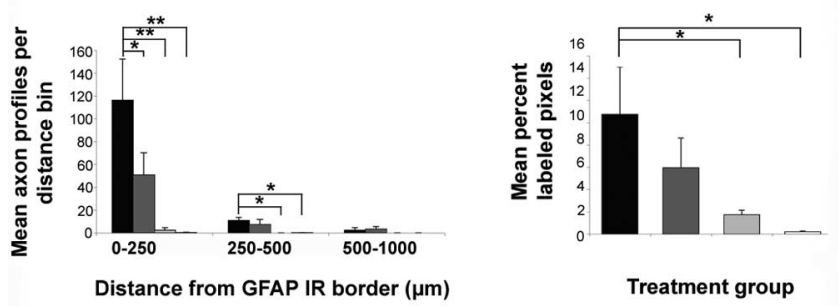

\begin{tabular}{|ll}
\hline MSC-NT3 + Lenti-NT3 (n=6) & $\square$ MSC-NT3 + Lenti-GFP (n=6) \\
$\square$ MSC + Lenti-NT3 (n=7) & $\square$ MSC + Lenti-GFP (n=5)
\end{tabular}

Figure 4. Quantification of CTB-labeled axonal profiles rostral to and within the lesion. Animals that received MSC-NT-3 graft cells combined with Lenti-NT-3 injections exhibited significantly more axonal profiles beyond the astrocyte-defined lesion border than animals from any other group $(\boldsymbol{A})$ and significantly higher axonal density within the lesion border than animals that received Lenti-GFP injections $(\boldsymbol{B})$ (ANOVA; ${ }^{*} p<0.05$, Fisher's post hoc analysis). Values are mean \pm SEM. IR, Immunoreactivity. ${ }^{* *} p<0.01$.

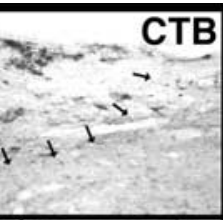

Lentiviral NT-3 gene transfer combined with marrow stromal cell grafts support bridging axonal regeneration across spinal cord lesion sites

We examined whether lentivirally generated NT-3 gradients would support growth of transected ascending sensory axons into and beyond a dorsal column lesion site. CTB-labeled ascending sensory axons were observed beyond the astrocytedefined lesion border only in animals receiving injections of Lenti-NT-3 vectors rostral to the lesion site (Fig. $3 A-C$ ). In addition, high-magnification images of CTB-labeled axons demonstrated that axons topographically associated with regions of NT-3-expressing vectortransduced cells (Fig. 3D-G).

Axons extending beyond the lesion site appeared to be regenerating rather than spared axons or axons that had circumvented the lesion site based on several observations. First, the morphology of axons extending beyond the lesion site was circuitous and their course was nonlinear, unlike intact axons. Second, axons bridged beyond the lesion border at all dorsoventral levels of the grafts, not only at the dorsal or ventralmost aspect in which spared axons might reside (Steward et al., 2003) (supplemental Fig. 2, available at www. jneurosci.org as supplemental material). Third, no CTB-labeled axonal profiles were observed ventral to the lesion site or in lateral unlesioned portions of the spinal cord. Fourth, sectioning of the medulla through the entire extent of the nucleus gracilis indicated an absence of CTB-labeled axons in all lesioned subjects, confirming that lesions were complete. In contrast, CTB injections in four intact rats (Table 1) showed the typical distribution of CTB label in the nucleus gracilis (supplemental Fig. 3, available at www.jneurosci.org as supplemental material).

We quantified bridging axons and axon density within cellular grafts in animal subjects in which the zone of vector transduction was within $100 \mu \mathrm{m}$ of the rostral lesion border (Fig. 4) (supplemental Fig. 4, available at www.jneurosci.org as supplemental material). Both groups of animals that received lentiviral vectors expressing NT-3 exhibited axons emerging rostrally from the MSC graft, whereas animals that received control Lenti-GFP vectors exhibited minimal to no axon growth beyond the graft (Fig. $4 A$ ). Statistically significant differences in axon bridging compared with control Lenti-GFP-injected animals were observed for up to $500 \mu \mathrm{m}$ in subjects that received Lenti-NT-3 vector injections combined with MSC-NT-3 graft cells. In addition, more axons were observed at the $0-250 \mu \mathrm{m}$ distance in this group than in the group that received naive MSC graft cells combined with Lenti-NT-3 vectors.

Within the graft, axon density was increased by the presence of MSC-NT-3 graft cells and to an even greater degree by injection of Lenti-NT-3 vectors rostrally (Fig. $4 B$ ). Lenti-NT-3 vector injections combined with MSC-NT-3 graft cells resulted in the highest axon density, significantly higher than both groups that received Lenti-GFP vectors. Among animals that received 
Lenti-GFP vectors, subjects with MSCNT-3 grafts exhibited a ninefold increase in graft axon density compared with subjects that received naive MSC grafts (Fig. $4 B$ ), indicating that graft cell expression of NT-3 increases axonal penetration of grafts. Consistent with previous data (Lu et al., 2003), axon density was significantly higher in MSC-NT-3 grafts than in MSC grafts when only Lenti-GFP groups were compared $(p=0.01)$. Nissl staining and immunohistochemical detection of BrdUprelabeled MSCs indicated that MSC and MSC-NT-3 cells survived and integrated at the lesion site (supplemental Fig. 5, available at www.jneurosci.org as supplemental material). Double labeling for BrdU and neural markers indicated that graft cells did not differentiate into cells of neural lineage.

\section{Regenerating axons extend and turn toward local sources of NT-3}

We observed axon extension beyond the lesion site only when Lenti-NT-3 vectors diffused the entire $2.5 \mathrm{~mm}$ distance from the rostral injection site to the lesion/graft site (13 of 21 Lenti-NT-3-injected animals). In these subjects, Lenti-NT-3transduced cells were evident within 100 $\mu \mathrm{m}$ of the host/lesion border (Fig. $5 A-C$ ). In the majority of these animals, some vector transduction of cells within the graft was also observed, but the extent of this transduction did not differ between LentiNT-3-injected groups (based on analysis of GFP density in grafts; $p=0.34$ ). When Lenti-NT-3 vector failed to diffuse to the lesion border, axons were not observed beyond the lesion site (Fig. 5D,E). Control Lenti-GFP-injected groups exhibited only rare axons extending beyond the graft, regardless of the distance of Lenti-GFP transduction from the lesion site (Fig. $5 F-H$ ). These results suggest that the ability of sensory axons to extend beyond a lesion site is highly sensitive to local availability of NT-3.

When we compared expression of the GFP reporter gene in Lenti-NT-3-injected animals with the topography of sensory axon growth distal to the lesion, axon extension was closely associated with regions of NT-3 expression. For example, when vector distribution was restricted to specific subregions of the dorsal columns rostral to the lesion site, axonal profiles preferentially extended into these regions (Figs. 5, 6). Thus, regenerating dorsal column sensory axons exhibit specific in vivo extension and directional growth toward local sources of growth factors, similar to findings of in vitro "turning assays" characterizing axonal responses to diffusible molecules (Gundersen and Barrett, 1979; Paves and Saarma, 1997).

Regenerating sensory axons do not extend for long distances despite the presence of extended NT-3 gradients

The preceding data indicate that regenerating sensory axons require immediate spatial availability of NT-3 adjacent to lesion/ graft sites to emerge from the inhospitable host/lesion interface, and that regenerating axons will extend preferentially into local regions expressing NT-3. Although this indicates that sensory axons are sensitive to NT-3 and exhibit directional growth toward NT-3 sources, axons nonetheless did not continue to grow along the extended gradients of NT-3 that were established in the spinal cord rostral to the lesion. Indeed, the number of axons bridging $200 \mu \mathrm{m}$ beyond the rostral lesion site was approximately half the number of axons crossing the rostral lesion interface, and this number was further reduced twofold at a distance of $300 \mu \mathrm{m}$ (supplemental Fig. 4, available at www.jneurosci.org as supplemental material). The maximum distance of axon growth in animals receiving Lenti-NT-3 vector was $1000 \mu \mathrm{m}$ beyond the lesion, whereas a continuing gradient of NT-3 extended beyond this point for an additional $1-1.5 \mathrm{~mm}$ (as indicated by ELISA) (Fig. 2). Instead of continuing growth rostrally, axons sprouted locally, creating a dense network of axonal profiles on reaching a region of high NT-3 expression rostral to the lesion (Fig. 6).

\section{Discussion}

The present findings demonstrate sensory axon sensitivity to local availability of growth factors after injury to the CNS. This sensitivity allows axons to emerge from cellular grafts placed in lesion sites. Axons exhibit specific association with local sources of NT-3, such that growth is dependent on spatial distributions of 


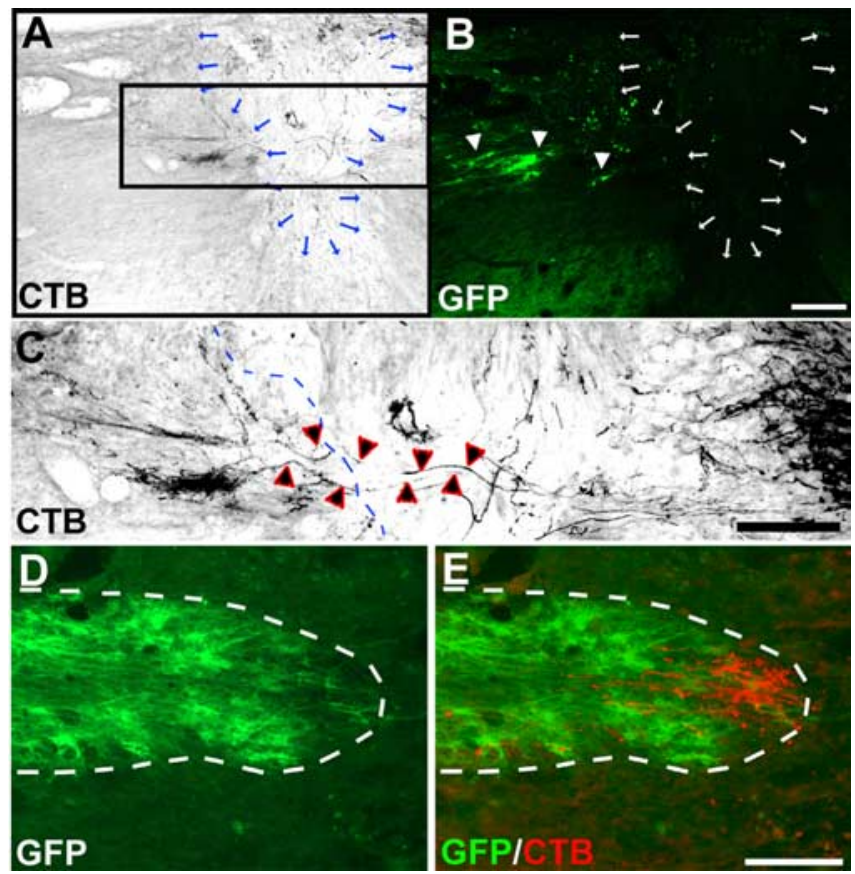

Figure 6. The topography of sensory axon bridging beyond the lesion site corresponds to the location of NT-3 lentiviral transduction. A, CTB-labeled axons (box) crossing the lesion extend beyond the lesion border (arrows), toward the region of dorsal column white matter in which cells have been transduced by Lenti-NT-3 vectors ( $\boldsymbol{B}$; arrowheads). $\boldsymbol{C}$, Axons can be traced from the main CTB-labeled tract at the caudal end of the lesion site, across the lesion site, and beyond the graft/host interface (dotted lines). $\boldsymbol{D}, 0$ n reaching areas of high NT-3 expression distal to a lesion site (outlined by dashed lines), axons (E; pseudocolored red) sprout locally. These axons do not extend for long distances within NT-3-expressing tissue. Scale bars: $\boldsymbol{A}, \boldsymbol{B}, 200 \mu \mathrm{m} ; \boldsymbol{C}, 140$ $\mu \mathrm{m} ; \boldsymbol{E}, \boldsymbol{F}, 100 \mu \mathrm{m}$

NT-3 expression beyond a lesion site. Although this growth parallels some features of in vitro turning assays that have shown growth cone or neurite extension toward diffusible chemotropic gradients (Letourneau, 1978; Gundersen and Barrett, 1979; Ming et al., 1997; Paves and Saarma, 1997; Genc et al., 2004), the growth we observed in vivo cannot be identified as strictly "chemotropic" in nature because axons failed to follow gradients of NT-3 that extended for long distances beyond the lesion cavity.

Although axons did emerge from MSC grafts in both groups of animals that received Lenti-NT-3 vectors, axon growth beyond lesion sites was significantly greater when NT-3 delivery occurred within and rostral to the graft. The functional significance of NT-3 expression by MSCs in the graft is uncertain but may have helped initiate the regenerative response by providing a source of NT-3 located immediately adjacent to the injured sensory axons at the distal host-graft interface. In addition, NT-3secreting MSCs in the lesion cavity actively express NT-3 at the time of grafting, whereas gene expression from injected lentiviral vectors becomes detectable no sooner than $24-48 \mathrm{~h}$ after transduction (Baekelandt et al., 2002). For these reasons, NT-3expressing MSCs may have enhanced recruitment of axons into the lesion site, increasing the number of axons in position to respond to the NT-3 delivered at more rostral sites. In support of this hypothesis, MSC-NT-3 grafts promoted ninefold more axonal growth into lesion sites than MSC grafts in control animals that received Lenti-GFP vectors. Alternatively, the greater axon growth in animals that received Lenti-NT-3/MSC-NT-3 treatment could have resulted from superior Lenti-NT-3 vector diffusion into the lesion/graft site compared with the Lenti-NT-3/ MSC group. However, quantification of GFP density in the lesion/graft site showed no difference between these groups, arguing against this possibility.

Axon growth extended beyond the lesion site in animals that received Lenti-NT-3 vectors but did not continue for long distances despite the presence of NT-3 gradients in the rostral spinal cord. There are several potential explanations for the lack of longdistance extension. Inhibitory molecules beyond the injured region create an environment that is nonpermissive for axonal extension over long distances. Inhibition related to the presence of astrocytes (McKeon et al., 1991), the extracellular matrix (Silver and Miller, 2004), and multiple myelin-associated molecules (Filbin, 2003) may counteract the stimulating influence of growth factors and terminate what might otherwise be continuing growth along a gradient of NT-3. Higher concentrations of NT-3 might overcome these inhibitory influences (Forander et al., 1994). Also, stimulatory factors other than NT-3 may be present in the immediate environment surrounding the lesion site that diminish as distance from the injury increases, thereby depleting the extending axon of a necessary stimulus to support long-distance growth. For example, macrophages accumulating around a lesion may constitute a local but not extended source of diffusible factors to support growth (Yin et al., 2003, 2006).

Alternatively, NT-3 may provide only very short-distance cues for axon growth or in fact signal termination of growth in certain situations, as suggested by studies of nervous system development (Ernfors and Persson, 1991; Chen and Frank, 1999; Tucker et al., 2001; Ma et al., 2002; Mori et al., 2002; Genc et al., 2004). Previous experiments indicate that, during development, DRG axon navigation toward peripheral targets involves dynamic changes in NT-3 expression, such that NT-3 levels are increased in regions in which axon tips are growing and decreased in these same regions as axons grow distally. Eventually, NT-3 expression is restricted to final target tissues (Farinas et al., 1996). Thus, sustained NT-3 expression, such as that generated by lentiviral expression, might represent saturating levels that send a "stop" signal for axon growth. A mechanism for decreasing NT-3 expression as axons reach one spatial location may be necessary to allow continued growth into more distant locations. Finally, although we detected an overall rostrocaudal NT-3 gradient by ELISA, lentivirus-transduced cells expressing NT-3 may create local microgradients of NT-3 as diffusion occurs. It is therefore possible that axons extend along microgradients for short distances and are unable to detect a more extended gradient.

We recently reported that the combination of NT-3 protein beyond a lesion site, together with augmentation of cAMP levels in the sensory neuronal soma, promoted longer-distance axonal growth than observed in the present study (Lu et al., 2004). This is notable because the magnitude and persistence of NT-3 delivery beyond the lesion site achieved in the current study likely exceeded by several-fold the amount of NT-3 delivered in our previous study, wherein $1 \mu \mathrm{g}$ of NT-3 protein was injected rostral to the lesion site at a single time point. However, the previous study achieved greater distances of sensory axonal growth, with axon extension over a $2 \mathrm{~mm}$ distance beyond the lesion cavity to the site of rostral NT-3 injection. However, the density of axon growth within regions of NT-3 delivery in the present study was higher than we observed in the previous study. This suggests that cAMP and NT-3 may fundamentally differ in their effects on the growth of injured axons in the adult CNS. Whereas cAMP may alter the intrinsic ability of adult axons to elongate, possibly by upregulating expression of growth-related genes or impairing responses to inhibitory environmental molecules (Gao et al., 2003), 
NT-3 may act at a more local and terminal level, inducing axonal sprouting and termination (Cafferty et al., 2001). Indeed, the morphology of axons extending densely into regions of NT-3 expression in the present study was fine and highly varicose, suggesting potential attempts to locate neuronal targets. Alternatively, as indicated in the preceding paragraph, the greater amounts of NT-3 delivered in the present study may simply have constituted saturating levels of growth factors to the extending axons, overwhelming the ability of the axon to sense a continued gradient.

The effects of NT-3 observed in the present study raise the possibility that the sole administration of this or other trophic factors at and beyond the injury site may not achieve the goal of long-distance axonal growth after SCI. If the biological role of the growth factor is indeed to provide a recognition signal for target reinnervation rather than a long-distance growth signal, a modified strategy would be required to promote substantial long-distance axonal regeneration. Combinatorial approaches to facilitate regeneration might be optimal, wherein nontropic agents recruit and stimulate the elongation of sufficient numbers of axons over biologically meaningful distances to reach an intended target, and trophic factors are administered into the specific target to induce elaboration of terminals and enhance target reinnervation. Future studies can be designed to test these possibilities.

\section{References}

Azizi SA, Stokes D, Augelli BJ, DiGirolamo C, Prockop DJ (1998) Engraftment and migration of human bone marrow stromal cells implanted in the brains of albino rats: similarities to astrocyte grafts. Proc Natl Acad Sci USA 95:3908-3913.

Baekelandt V, Claeys A, Eggermont K, Lauwers E, De Strooper B, Nuttin B, Debyser Z (2002) Characterization of lentiviral vector-mediated gene transfer in adult mouse brain. Hum Gene Ther 13:841-853.

Bamber NI, Li H, Lu X, Oudega M, Aebischer P, Xu XM (2001) Neurotrophins BDNF and NT-3 promote axonal re-entry into the distal host spinal cord through Schwann cell-seeded mini-channels. Eur J Neurosci $13: 257-268$

Blesch A (2004) Lentiviral and MLV based retroviral vectors for ex vivo and in vivo gene transfer. Methods 33:164-172.

Blesch A, Yang H, Weidner N, Hoang A, Otero D (2004) Axonal responses to cellularly delivered NT-4/5 after spinal cord injury. Mol Cell Neurosci 27:190-201.

Blits B, Dijkhuizen PA, Boer GJ, Verhaagen J (2000) Intercostal nerve implants transduced with an adenoviral vector encoding neurotrophin-3 promote regrowth of injured rat corticospinal tract fibers and improve hindlimb function. Exp Neurol 164:25-37.

Bradbury EJ, Khemani S, Von R, King, Priestley JV, McMahon SB (1999) NT-3 promotes growth of lesioned adult rat sensory axons ascending in the dorsal columns of the spinal cord. Eur J Neurosci 11:3873-3883.

Cafferty WB, Gardiner NJ, Gavazzi I, Powell J, McMahon SB, Heath JK, Munson J, Cohen J, Thompson SW (2001) Leukemia inhibitory factor determines the growth status of injured adult sensory neurons. J Neurosci 21:7161-7170.

Chen HH, Frank E (1999) Development and specification of muscle sensory neurons. Curr Opin Neurobiol 9:405-409.

Coumans JV, Lin TT, Dai HN, MacArthur L, McAtee M, Nash C, Bregman BS (2001) Axonal regeneration and functional recovery after complete spinal cord transection in rats by delayed treatment with transplants and neurotrophins. J Neurosci 21:9334-9344.

Dontchev VD, Letourneau PC (2002) Nerve growth factor and semaphorin $3 \mathrm{~A}$ signaling pathways interact in regulating sensory neuronal growth cone motility. J Neurosci 22:6659-6669.

Ernfors P, Persson H (1991) Developmentally regulated expression of HDNF/NT-3 mRNA in rat spinal cord motoneurons and expression of BDNF mRNA in embryonic dorsal root ganglion. Eur J Neurosci 3:953-961.

Farinas I, Yoshida CK, Backus C, Reichardt LF (1996) Lack of neurotrophin-3 results in death of spinal sensory neurons and premature differentiation of their precursors. Neuron 17:1065-1078.

Filbin MT (2003) Myelin-associated inhibitors of axonal regeneration in the adult mammalian CNS. Nat Rev Neurosci 4:703-713.

Forander P, Bjorklund L, Stromberg I (1994) Dose-dependent effects of recombinant human NGF on grafted adult adrenal medullary tissue. Exp Neurol 126:168-177.

Gallo G, Lefcort FB, Letourneau PC (1997) The trkA receptor mediates growth cone turning toward a localized source of nerve growth factor. J Neurosci 17:5445-5454.

Gao Y, Nikulina E, Mellado W, Filbin MT (2003) Neurotrophins elevate cAMP to reach a threshold required to overcome inhibition by MAG through extracellular signal-regulated kinase-dependent inhibition of phosphodiesterase. J Neurosci 23:11770-11777.

Genc B, Ozdinler PH, Mendoza AE, Erzurumlu RS (2004) A chemoattractant role for NT-3 in proprioceptive axon guidance. PLoS Biol 2:e403.

Grill R, Murai K, Blesch A, Gage FH, Tuszynski MH (1997a) Cellular delivery of neurotrophin-3 promotes corticospinal axonal growth and partial functional recovery after spinal cord injury. J Neurosci 17:5560-5572.

Gundersen RW, Barrett JN (1979) Neuronal chemotaxis: chick dorsal-root axons turn toward high concentrations of nerve growth factor. Science 206:1079-1080.

Himes BT, Liu Y, Solowska JM, Snyder EY, Fischer I, Tessler A (2001) Transplants of cells genetically modified to express neurotrophin-3 rescue axotomized Clarke's nucleus neurons after spinal cord hemisection in adult rats. J Neurosci Res 65:549-564.

Houweling DA, Lankhorst AJ, Gispen WH, Bar PR, Joosten EA (1998) Collagen containing neurotrophin-3 (NT-3) attracts regrowing injured corticospinal axons in the adult rat spinal cord and promotes partial functional recovery. Exp Neurol 153:49-59.

Jakeman LB, Wei P, Guan Z, Stokes BT (1998) Brain-derived neurotrophic factor stimulates hindlimb stepping and sprouting of cholinergic fibers after spinal cord injury. Exp Neurol 154:170-184.

Kirik D, Rosenblad C, Bjorklund A (2000) Preservation of a functional nigrostriatal dopamine pathway by GDNF in the intrastriatal 6-OHDA lesion model depends on the site of administration of the trophic factor. Eur J Neurosci 12:3871-3882.

Kobayashi NR, Fan DP, Giehl KM, Bedard AM, Wiegand SJ, Tetzlaff W (1997) BDNF and NT-4/5 prevent atrophy of rat rubrospinal neurons after cervical axotomy, stimulate GAP-43 and T $\alpha 1$-tubulin mRNA expression, and promote axonal regeneration. J Neurosci 17:9583-9595.

Letourneau PC (1978) Chemotactic response of nerve fiber elongation to nerve growth factor. Dev Biol 66:183-196.

Liu Y, Kim D, Himes BT, Chow SY, Schallert T, Murray M, Tessler A, Fischer I (1999a) Transplants of fibroblasts genetically modified to express BDNF promote regeneration of adult rat rubrospinal axons and recovery of forelimb function. J Neurosci 19:4370-4387.

Liu Y, Himes BT, Solowska J, Moul J, Chow SY, Park KI, Tessler A, Murray M, Snyder EY, Fischer I (1999b) Intraspinal delivery of neurotrophin-3 using neural stem cells genetically modified by recombinant retrovirus. Exp Neurol 158:9-26.

Lu P, Blesch A, Tuszynski MH (2001) Neurotrophism without neurotropism: BDNF promotes survival but not growth of lesioned corticospinal neurons. J Comp Neurol 436:456-470.

Lu P, Jones LL, Snyder EY, Tuszynski MH (2003) Neural stem cells constitutively secrete neurotrophic factors and promote extensive host axonal growth after spinal cord injury. Exp Neurol 181:115-129.

Lu P, Yang H, Jones LL, Filbin MT, Tuszynski MH (2004) Combinatorial therapy with neurotrophins and cAMP promotes axonal regeneration beyond sites of spinal cord injury. J Neurosci 24:6402-6409.

Lu P, Jones LL, Tuszynski MH (2005) BDNF-expressing marrow stromal cells support extensive axonal growth at sites of spinal cord injury. Exp Neurol 191:344-360.

Ma L, Harada T, Harada C, Romero M, Hebert JM, McConnell SK, Parada LF (2002) Neurotrophin-3 is required for appropriate establishment of thalamocortical connections. Neuron 36:623-634.

McKeon RJ, Schreiber RC, Rudge JS, Silver J (1991) Reduction of neurite outgrowth in a model of glial scarring following CNS injury is correlated with the expression of inhibitory molecules on reactive astrocytes. J Neurosci 11:3398-3411.

Menei P, Montero-Menei C, Whittemore SR, Bunge RP, Bunge MB (1998) Schwann cells genetically modified to secrete human BDNF promote en- 
hanced axonal regrowth across transected adult rat spinal cord. Eur J Neurosci 10:607-621.

Ming G, Lohof AM, Zheng JQ (1997) Acute morphogenic and chemotropic effects of neurotrophins on cultured embryonic Xenopus spinal neurons. J Neurosci 17:7860-7871.

Mori T, Yamashita D, Homma KJ, Shimizu K, Hayashi M (2002) Changes in NT-3 and TrkC in the primary visual cortex of developing macaques. NeuroReport 13:1689-1694.

Naldini L, Blomer U, Gage FH, Trono D, Verma IM (1996) Efficient transfer, integration, and sustained long-term expression of the transgene in adult rat brains injected with a lentiviral vector. Proc Natl Acad Sci USA 93:11382-11388.

Niwa H, Yamamura K, Miyazaki J (1991) Efficient selection for highexpression transfectants with a novel eukaryotic vector. Gene 108:193-199.

Paves H, Saarma M (1997) Neurotrophins as in vitro growth cone guidance molecules for embryonic sensory neurons. Cell Tissue Res 290:285-297.

Pfeifer A, Ikawa M, Dayn Y, Verma IM (2002) Transgenesis by lentiviral vectors: lack of gene silencing in mammalian embryonic stem cells and preimplantation embryos. Proc Natl Acad Sci USA 99:2140-2145.

Plunet W, Kwon BK, Tetzlaff W (2002) Promoting axonal regeneration in the central nervous system by enhancing the cell body response to axotomy. J Neurosci Res 68:1-6.

Ramer MS, Priestley JV, McMahon SB (2000) Functional regeneration of sensory axons into the adult spinal cord. Nature 403:312-316.

Ringstedt T, Kucera J, Lendahl U, Ernfors P, Ibanez CF (1997) Limb proprioceptive deficits without neuronal loss in transgenic mice overexpressing neurotrophin-3 in the developing nervous system. Development 124:2603-2613.

Romero MI, Rangappa N, Garry MG, Smith GM (2001) Functional regeneration of chronically injured sensory afferents into adult spinal cord after neurotrophin gene therapy. J Neurosci 21:8408-8416.

Ruitenberg MJ, Plant GW, Hamers FP, Wortel J, Blits B, Dijkhuizen PA, Gispen WH, Boer GJ, Verhaagen J (2003) Ex vivo adenoviral vectormediated neurotrophin gene transfer to olfactory ensheathing glia: effects on rubrospinal tract regeneration, lesion size, and functional recovery after implantation in the injured rat spinal cord. J Neurosci 23:7045-7058.

Schnell L, Schneider R, Kolbeck R, Barde YA, Schwab ME (1994) Neurotrophin-3 enhances sprouting of corticospinal tract during development and after adult spinal cord lesion. Nature 367:170-173.

Silver J, Miller JH (2004) Regeneration beyond the glial scar. Nat Rev Neurosci 5:146-156.

Snider WD, Zhou FQ, Zhong J, Markus A (2002) Signaling the pathway to regeneration. Neuron 35:13-16.

Steward O, Zheng B, Tessier-Lavigne M (2003) False resurrections: distin- guishing regenerated from spared axons in the injured central nervous system. J Comp Neurol 459:1-8.

Tessarollo L, Coppola V, Fritzsch B (2004) NT-3 replacement with brainderived neurotrophic factor redirects vestibular nerve fibers to the cochlea. J Neurosci 24:2575-2584.

Tessier-Lavigne M (1994) Axon guidance by diffusible repellants and attractants. Curr Opin Genet Dev 4:596-601.

Tetzlaff W, Kobayashi NR, Giehl KM, Tsui BJ, Cassar SL, Bedard AM (1994) Response of rubrospinal and corticospinal neurons to injury and neurotrophins. Prog Brain Res 103:271-286.

Tokumine J, Kakinohana O, Cizkova D, Smith DW, Marsala M (2003) Changes in spinal GDNF, BDNF, and NT-3 expression after transient spinal cord ischemia in the rat. J Neurosci Res 74:552-561.

Tucker KL, Meyer M, Barde YA (2001) Neurotrophins are required for nerve growth during development. Nat Neurosci 4:29-37.

Tuszynski MH, Gabriel K, Gage FH, Suhr S, Meyer S, Rosetti A (1996) Nerve growth factor delivery by gene transfer induces differential outgrowth of sensory, motor, and noradrenergic neurites after adult spinal cord injury. Exp Neurol 137:157-173.

Tuszynski MH, Grill R, Jones LL, McKay HM, Blesch A (2002) Spontaneous and augmented growth of axons in the primate spinal cord: effects of local injury and nerve growth factor-secreting cell grafts. J Comp Neurol 449:88-101.

Xu XM, Guenard V, Kleitman N, Aebischer P, Bunge MB (1995) A combination of BDNF and NT-3 promotes supraspinal axonal regeneration into Schwann cell grafts in adult rat thoracic spinal cord. Exp Neurol 134:261-272.

Yang H, Lu P, McKay HM, Bernot T, Keirstead H, Steward O, Gage FH, Edgerton VR, Tuszynski MH (2006) Endogenous neurogenesis replaces oligodendrocytes and astrocytes after primate spinal cord injury. J Neurosci 26:2157-2166.

Ye JH, Houle JD (1997) Treatment of the chronically injured spinal cord with neurotrophic factors can promote axonal regeneration from supraspinal neurons. Exp Neurol 143:70-81.

Yin Y, Cui Q, Li Y, Irwin N, Fischer D, Harvey AR, Benowitz LI (2003) Macrophage-derived factors stimulate optic nerve regeneration. J Neurosci 23:2284-2293.

Yin Y, Henzl MT, Lorber B, Nakazawa T, Thomas TT, Jiang F, Langer R, Benowitz LI (2006) Oncomodulin is a macrophage-derived signal for axon regeneration in retinal ganglion cells. Nat Neurosci 9:843-852.

Zhang Y, Dijkhuizen PA, Anderson PN, Lieberman AR, Verhaagen J (1998) NT-3 delivered by an adenoviral vector induces injured dorsal root axons to regenerate into the spinal cord of adult rats. J Neurosci Res 54:554-562.

Zhou L, Baumgartner BJ, Hill-Felberg SJ, McGowen LR, Shine HD (2003) Neurotrophin-3 expressed in situ induces axonal plasticity in the adult injured spinal cord. J Neurosci 23:1424-1431. 